\title{
A família Nymphaeaceae no estado do Ceará, Brasil
}

\author{
The family Nymphaeaceae in Ceara state, Brazil
}

Danilo José Lima de Sousa ${ }^{1,2}$ \& Lígia Queiroz Matias ${ }^{1}$

\begin{abstract}
Resumo
No estado do Ceará, onde predomina um clima Tropical Quente Semiárido, são observados diferentes tipos de corpos d'água. Nestes são frequentemente encontrados representantes de Nymphaeaceae. Dos seis gêneros da família apenas Nymphaea ocorre no Ceará. Foram identificadas sete espécies de Nymphaea: $N$. amazonum e $N$. lasiophylla possuem uma ampla distribuição, estando presentes desde a zona costeira ao interior do estado; $N$. jamesoniana, $N$. lingulata e $N$. pulchella ocorreram nas regiões semiáridas no interior do estado; $N$. rudgeana e $N$. tenerinervia apresentaram populações apenas nos ambientes litorâneos. $N$. lasiophylla é a espécie mais frequente. São apresentadas descrições, comentários, ilustrações e chaves de identificação dos táxons.
\end{abstract}

Palavras-chave: áreas inundadas, florística, macrófitas aquáticas, regiões semiáridas.

\begin{abstract}
In Ceará predominates a hot semiarid tropical climate. Different kinds of water courses can be found in the state, and representatives of Nymphaeaceae are frequently found on these. Of six genera belonging to this family, only Nymphaea occurs in Ceará. A total of seven Nymphaea species were identified. Nymphaea amazonum and $N$. lasiophylla have a wide distribution and occur from the coast to the interior of the state; $N$. jamesoniana, $N$. lingulata and $N$. pulchella are found in the semiarid regions of the interior of the state; $N$. rudgeana and $N$. tenerinervia have populations in coastal environments only. Nymphaea lasiophylla is the most frequent species. We present descriptions, comments, illustrations and identification keys for the taxa.
\end{abstract}

Key words: wetlands, floristics, aquatic macrophytes, semiarid regions.

\section{Introdução}

Nymphaeaceae encontra-se na ordem Nymphaeales, constituindo um grupo monofilético e associado à Cabombaceae e Hydatellaceae (Löhne et al. 2007; APG III 2009; Reveal \& Chase 2011). É constituída por seis gêneros distribuídos por todo o mundo. Nymphaea L. é pantropical; Nuphar J.E. Smith ocorre na América do Norte, Ásia e Europa; Barclaya Wallich e Euryale Salisb. são restritas à Ásia; enquanto que Ondinea Hartog e Victoria J. Lindley são restritas, respectivamente, à Austrália e à América do Sul. (Yoo et al. 2005).
No Brasil, Victoria ocorre na Amazônia e no Pantanal e Nymphaea apresenta populações distribuídas por todo o país, constituindo o gênero mais representativo, com 18 espécies (Souza \& Lorenzi 2008; Amaral 2012). No nordeste brasileiro ocorre apenas o gênero Nymphaea, onde foram registradas dez espécies, das quais cinco são indicadas para o Ceará (Amaral 2006, 2012).

Estudos filogenéticos realizados com o gênero Nymphaea demonstram que este se trata de um grupo parafilético em relação à Ondinea e ao clado formado por Victoria e Euryale (Borsch et al. 2003; Löhne et

\footnotetext{
${ }^{1}$ Universidade Federal do Ceará, Centro de Ciências, Depto. Biologia, Lab. Taxonomia de Angiospermas, bl. 906, Campus do Pici, 60451-760, Fortaleza, CE, Brasil.

${ }^{2}$ Autor para correspondência: danilojls@yahoo.com.br
} 
al. 2007; Borsch et al. 2008). A partir de características dos carpelos, o gênero foi tratado por Conard (1905) em dois grandes grupos (1) Apocarpiae (sect. Leptopleura sensu Caspary 1878) que compreende os subgêneros Anecphya e Brachycera com gineceu apocárpico ou com ovários levemente adnatos; (2) Syncarpiae (sect. Symphytopleura sensu Caspary 1878) onde são agrupados os subgêneros Nymphaea, Lotos e Hydroclallis, estes com gineceu sincárpico. Recentemente, algumas espécies do subgênero Anecphya foram reagrupadas em um novo subgênero, Confluentes, devido à presença de rizomas verticais, transição gradual de pétalas para estames, apêndices estigmatíferos ausentes ou diminutos, além de características das sementes (Jacobs \& Porter 2007).

Graças à sua importância ecológica (Pott \& Pott 2000), cultural (Krell et al. 2003; Bertol et al. 2004; Endress 2010) e científica (Les et al. 1991; Les et al. 1999), a família tem sido abordada em diversos inventários florísticos pelo mundo (Duke 1963; Wiersema 1987; Dezhi et al. 2011; Hyde et al. 2012) e em análises filogenéticas (Ito 1987; Löhne et al. 2007).

No Ceará o número de trabalhos realizados com a flora aquática vem aumentando nos últimos anos (Matias et al. 2003; Matias \& Irgang 2006; Matias 2007, 2010; Matias \& Sousa 2011), porém nenhum deles trata da família Nymphaeaceae. Desta forma este trabalho teve como objetivo levantar as espécies da família Nymphaeaceae ocorrentes no Ceará, bem como descrever o padrão de distribuição geográfica no estado, visando uma nova contribuição para o conhecimento da flora aquática local e nacional.

\section{Material e Métodos}

Espécimes coletados em expedições esporádicas, realizadas principalmente no período chuvoso, e materiais depositados nos herbários EAC, GH, INPA, IPA, MO, R, UNA (as siglas seguem Thiers, continuamente atualizado) foram analisados para o desenvolvimento do presente trabalho. A identificação foi realizada através de consulta a bibliografia específica (Conard 1905; Wiersema 1987; Pott 1998; Pott \& Pott 2000). Os espécimes coletados foram herborizados seguindo a metodologia de Haynes (1984) e Ceska (1986) e depositados no Herbário EAC. Os nomes dos autores estão de acordo com IPNI (continuamente atualizado). A terminologia segue Radford et al. (1974), Harris \& Harris (1994), Wiersema (1987) e Sculthorpe (1967). A classificação taxonômica está baseada no Angiosperm Phylogeny Group (APG III 2009). Os dados de distribuições geográfica das espécies foram extraídos de Wiersema (1987), Conard (1905), Wiersema et al. (2008) e Amaral (2012), além da análise dos espécimes coletados e dados de herbários. Para a demonstração da distribuição das espécies no estado foi utilizado o mapa em quadrículas (Fig. 1), padrão para o projeto Flora do Ceará.

\section{Resultados e Discussão}

Tratamento taxonômico Nymphaeaceae Salisb., Ann. Bot. (König \& Sims) 2: 70.1805 .

Ervas aquáticas rizomatosas. Folhas alternas ou espiraladas, simples, peltadas ou subpeltadas, margem inteira, irregular ou serreada, flutuante ou raramente emergente, nervação reticulada a palmada, estípulas presentes ou ausentes. Flores solitárias, monóclinas e radiais, longo pediceladas, geralmente flutuando na lâmina d'água ou ainda acima desta; sépalas 4; pétalas 5-20, livres, imbricadas; estames petalóides numerosos, os mais internos ocasionalmente estaminódios; carpelos 3 a numerosos, sincárpicos, apocárpicos ou ainda levemente conatos na base, ovário súpero, placentação laminar, estigmas amplos formando um disco expandido, sésseis, frequentemente rodeados por apêndices estigmatíferos que podem ser incospícuos ou conspícuos, lingulados a fortemente clavados; óvulos numerosos, anátropos. Frutos carnosos indeiscentes ou com deiscência irregular. Sementes numerosas, frequentemente com arilo campanulado aerífero. 


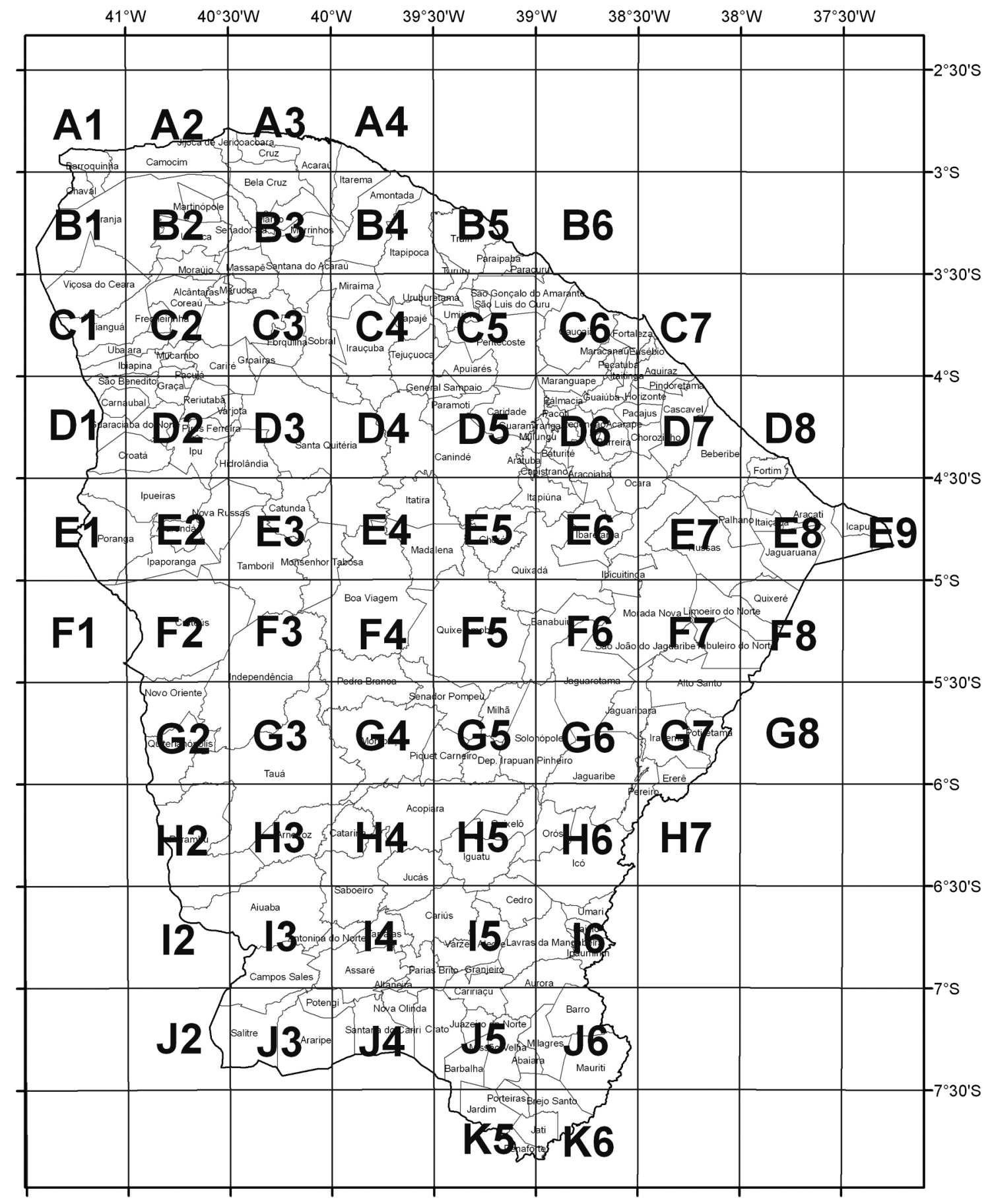

Figura 1 - Mapa do estado do Ceará (CE), Brasil, evidenciando o sistema de quadrículas georreferenciadas. Figure 1 - Map of Ceará state (CE), Brazil, showing the system of georeferenced squares grid. 


\section{Chave para identificação das espécies de Nymphaeaceae do Ceará}

1. Gineceu apocárpico ou com carpelos levemente conatos, antese diurna, apêndices estigmatíferos curtos, $1,5-3,0 \mathrm{~mm}$, triangulares 5. N. pulchella

1'. Gineceu sincárpico, antese noturna, apêndices estigmatíferos relativamente longos, 4,0-13,0 mm, clavados ou lingulados.

2. Apêndices estigmatíferos lingulados, transição abrupta de pétala para estame.

3. Tricoesclereídes ausentes no mesofilo foliar, apêndices estigmatíferos com ápice vináceo e base creme, pseudoestolhos submersos presentes 3. N. lasiophylla

3' Tricoesclereídes presentes no mesofilo foliar, apêndices estigmatíferos com ápice creme e base vinácea, pseudoestolhos submersos ausentes 4. N. lingulata

2'. Apêndices estigmatíferos clavados, transição gradual de pétala para estame.

4. Folhas com margem denteada ou ondulada, ápice dos lobos denteado, apêndices estigmatíferos pardos 6. N. rudgeana

4'. Folhas com margem inteira, ápice dos lobos arredondado, agudo ou mucronado, apêndices estigmatíferos rosáceos a vináceos com ápice e base creme ou pardos, ápice rosáceo

5. Presença de estaminódios petaloides; apêndices estigmatíferos eretos, tricoesclereídes bifurcados 7. N. tenerinervia

5'. Ausência de estaminódios petaloides; apêndices estigmatíferos curvados, tricoesclereídes, quando presentes, não bifurcados

6. Folhas elípticas; nervação actinódroma aracnóide; ausência de anel de tricomas na inserção do pecíolo ao limbo foliar 2. N. jamesoniana

6'. Folhas arredondadas a ovaladas; nervação actinódroma, não aracnóide; presença de anel de tricomas na inserção do pecíolo ao limbo foliar 1. N. amazonum

1. Nymphaea amazonum Mart. \& Zucc. Abh. Math.-Phys. Cl. Königl. Bayer. Akad. Wiss. 1: 363. 1832.

Fig. 2a-d

Rizoma cilíndrico, 2,5-3,0 cm diâm. Folhas arredondadas a ovaladas; 8,0-16,5 ×6,5-14,3 cm; margem inteira; ápice arredondado; base cordada; lobos com ápice agudo, frequentemente imbricados; face adaxial verde frequentemente com margens vináceas, raramente com máculas enegrecidas, esclereídes 14-24 por $\mathrm{mm}^{2}$, tricoesclereídes ausentes; face abaxial vinácea ou esverdeada com máculas enegrecidas; nervação actinódroma não aracnóide, nervuras primárias 15-17; pecíolo 2,04,0 mm diâm., glabro; presença de anel de tricomas na inserção do pecíolo. Flores flutuantes na lâmina d'água ou 3,0-5,0 cm acima da lâmina d'água, antese noturna, pseudoestolhos ausentes; pedicelo 3,0-4,0 mm diâm., glabro; sépalas 4, elípticas, 4,0-6,0 × 1,3-2,6 cm, verdes com máculas vináceas, tricoesclereídes presentes; pétalas 16-24, elípticas a ovaladas, 3,0-4,5 × 1,3-2,6 cm, alvas, tricoesclereídes ausentes, transição de pétalas para estames gradual; estaminódios petaloides ausentes; estames 100-120, alvos, os mais externos 3,3-4,0 $\times 1,6-2,0 \mathrm{~cm}$, os mais internos $0,8-1,8 \times 0,1-0,3$ $\mathrm{cm}$, tricoesclereídes ausentes; carpelos 26-40, completamente adnatos; apêndices estigmatíferos longos, 4,0-13,0 mm compr., clavados, curvados, pardos com ápice rosáceo; raios estigmáticos 0,6-1,0 cm. diâm., alaranjados. Frutos bagas, submersas. Sementes numerosas, 1,0-1,4 mm compr., arilo aerífero campanulado, translúcido. Material examinado: Caucaia, 29.X.2008, D.J.L. Sousa 64 (EAC). Fortaleza, 26.IX.1935, fl., F. Drouet 2511 (GH). Fortim, 11.X.2011, fl., D.J.L. Sousa (EAC). Icapuí, 12.X.2011, fl., D.J.L. Sousa 142 (EAC). Iguatu, 6.IX.2009, fl., L.Q. Matias 578 (EAC). Jijoca de Jericoacoara, 23.VIII.2000, fl., L.Q. Matias 312 (EAC). Quixeramobim, 13.V.2011, fl., D. J. L. Sousa 131 (EAC). São Gonçalo do Amarante, 4.X.2010, fl., A.S.F. Castro 2352 (EAC). Sobral, 8.XI.2007, fl., L.Q. Matias 570 (EAC). Varjota, 9.V.2011, fl., D.J.L. Sousa 120 (EAC). 29.VI.1982, fl., J.H. Wiersema et al. 2312 (IPA, UNA).

Presente na faixa tropical da América do Sul e nas ilhas do Caribe, principalmente em planícies adjacentes às zonas costeiras (Wiersema 1987). Pode ser encontrada em 13 estados brasileiros, distribuídos no Norte, Nordeste, Centro-Oeste e Sudeste do país (Amaral 2012). No estado do Ceará apresenta populações na região costeira e no interior do estado, em pequenos alagados nas margens de estradas e em corpos d'água artificiais. A espécie também pode ser encontrada em ambientes lênticos em altitudes mais 

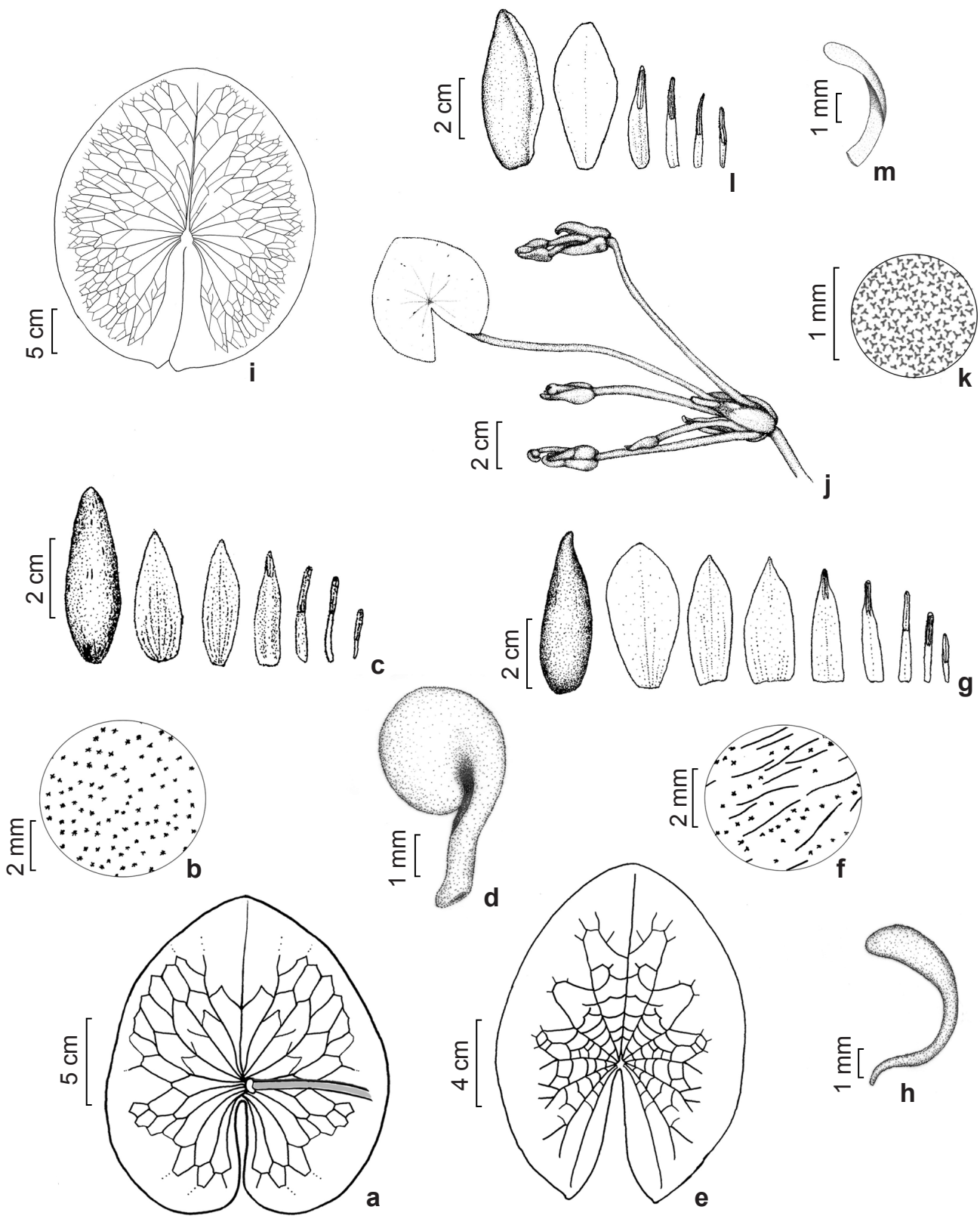

Figura 2 - a-d. Nymphaea amazonum (Sousa 64) - a. face abaxial do limbo foliar evidenciando a nervação; b. detalhe da face adaxial do limbo foliar evidenciando a presença de macroesclereídes e a ausência de tricoesclereídes; c. peças florais evidenciando a transição gradual de pétalas para estames; d. apêndice estigmatífero. e-h. N. jamesoniana (Normando 520) - e. face abaxial do limbo foliar evidenciando a nervação; f. detalhe da face adaxial do limbo foliar evidenciando a presença de macroesclereídes e de tricoesclereídes; g. peças florais, evidenciando a transição gradual de pétalas para estames; h. apêndice estigmatífero. i-m. Nymphaea lasiophylla (Sousa 75) - i. face abaxial do limbo foliar evidenciando a nervação; j. pseudoestolho; k. detalhe da face adaxial do limbo foliar evidenciando a presença de macroesclereídes e a ausência de tricoesclereídes; 1. peças florais evidenciando a transição abrupta de pétalas para estames; $m$. apêndice estigmatífero.

Figure 2 - a-d. Nymphaea amazonum (Sousa 64) - a. abaxial surface of leaf blade showing the venation; b. detail of adaxial side of leaf blade showing the presence of macrosclereids and absence of trichosclereid c. floral parts showing the gradual transition from petals to stamens; d. Estigmatiferous appendix. e-h. N. jamesoniana (Normando 520) - e. abaxial surface of leaf blade showing the venation; f. detail of adaxial side of leaf blade showing the presence of macrosclereids and trichosclereid g. floral parts, showing the gradual transition from petals to stamens; h. estigmatiferous appendix. i-m. Nymphaea lasiophylla (Sousa 75) - i. abaxial surface of leaf blade showing the venation; j. pseudo stolon; $k$. detail of adaxial side of leaf blade showing the presence of macrosclereids and absence of trichosclereid; 1 . floral parts showing the abrupt transition from petals to stamens; $\mathrm{m}$. estigmatiferous appendix. 
elevadas (Fig. 1 - A3, C3, C5, C6). Diferencia-se pela presença de um anel de tricomas na inserção do pecíolo no limbo foliar e pelos seus apêndices estigmatíferos bastante desenvolvidos e fortemente curvados, com ápice rosáceo. Para a espécie são descritas duas subespécies: $N$. amazonum subsp. amazonum com maior densidade de macroesclereides visualizados na face adaxial da folha, onde estão ausentes os tricoesclereídes e um número inferior a 200 estames, e $N$. amazonum subsp. pedersenii Wiersema com poucos esclereides, presença de tricoesclereídes e frequentemente possuindo mais de 225 estames (Wiersema 1987). No Ceará foi registrada apenas $N$. amazonum subsp. amazonum.

\section{Nymphaea jamesoniana Planch. Fl. Serres Jard.} Eur. 8:120. 1853.

Fig. 2e-h

Rizoma cilíndrico a botuliforme, ca. 1,7 $\mathrm{cm}$ diâm. Folhas elípticas a levementes ovaladas; $11,0-21,0 \times 8,8-14,1 \mathrm{~cm}$; margem inteira; ápice arredondado; base levemente cordada a sagitada; lobos com ápice mucronado, não imbricados; face adaxial verde, esclereídes $6-17$ por $\mathrm{mm}^{2}$, tricoesclereídes ca. 2 por $\mathrm{mm}^{2}$; face abaxial verde; nervação actinódroma aracnóide, nervuras primárias ca. 13; pecíolo 3,0-6,0 mm diâm; glabro; ausência de anel de tricomas na inserção do pecíolo. Flores flutuantes na lâmina d'água, antese noturna, pseudoestolhos ausentes; pedicelo $4,0-6,0 \mathrm{~mm}$ diâm., glabro; sépalas 4, ovaladas, 5,3-7,0×2,3-3,7 cm, verdes com base amarelada, tricoesclereídes presentes; pétalas 20-24, ovaladas, 3,9-6,0 × 1,8-2,2 cm, alvas, as mais externas esverdeadas, tricoesclereídes presentes, transição de pétalas para estames gradual; estaminódios petaloides ausentes; estames 80-94, alvos, os mais externos $2,8-4,6 \times 0,8-1,8 \mathrm{~cm}$, os mais internos $0,8-2,0 \times 0,2-0,3 \mathrm{~cm}$, tricoesclereídes presentes; carpelos 12-22, completamente adnatos; apêndices estigmatíferos longos, 8,0-9,0 mm compr., clavados, curvados, levemente rosáceos com ápice e base alva; raios estigmáticos $0,8-1,5 \mathrm{~cm}$ diâm., pardos. Frutos bagas, flutuantes na lâmina d'água. Sementes numerosas, $0,3-0,8 \mathrm{~mm}$ compr., arilo aerífero campanulado, translúcido.

Material examinado: Fortaleza, fl., Wiersema et al. 2315 (IPA,UNA). Iguatu, 18.V.2010, fl., L.R.O. Normando 520 (EAC). Quixeramobim,13.V.2011, fl., D.J.L. Sousa 135 (EAC).

Pode ser encontrada na região tropical e subtropical da América do Sul (Wiersema 1987). Possui registro para as Regiões Centro-Oeste e Nordeste do Brasil (Amaral 2012). Para o estado do
Ceará encontra-se restrita na região central do estado (Fig. 1 - C6, F5, H5), principalmente em áreas pouco degradadas, sendo de extrema importância a preservação destas regiões para a ocorrência da espécie. É facilmente diferenciada das demais espécies pela sua nervação actinódroma aracnóide e pelas bagas flutuantes na lâmina d'água, facilitando a sua dispersão por aves.

3. Nymphaea lasiophylla Mart. \& Zucc. Abh. Math. -Phys. Cl.Königl. Bayer. Akad Wiss. 1: 364. 1832.

Fig. 2i-m

Rizoma cilíndrico, 1,5-2,5 cm diâm. Folhas ovaladas a amplo ovaladas, raro arredondadas; $10,5-29,0 \times 8,3-26,0 \mathrm{~cm}$; margem inteira; ápice arredondado, levemente mucronado; base cordada a levemente sagitada; lobos com ápice mucronado, raramente imbricados; face adaxial verde raramente com máculas vináceas, esclereídes $14-20$ por $\mathrm{mm}^{2}$, tricoesclereídes ausentes; face abaxial verde a levemente vinácea; nervação actinódroma não aracnóide, nervuras primárias 15-17; pecíolo 2,5-5,0 mm diâm; glabro; ausência de anel de tricomas na inserção do pecíolo. Flores flutuantes na lâmina d'água, antese noturna, pseudoestolhos presentes; pedicelo 3,0-5,0 mm diâm., glabro; sépalas 4 , ovaladas a amplo elípticas, 3,6-7,0 $\times 1,8-2,3 \mathrm{~cm}$, verdes, raramente com máculas vináceas, tricoesclereídes presentes; pétalas 18-22, ovaladas a amplo elípticas, 3,5-7,3 × 1,9-2,8 $\mathrm{cm}$, alvas a pardas, as mais externas levemente esverdeadas, tricoesclereídes presentes, transição de pétalas para estames abrupta; estaminódios petaloides ausentes; estames 80-135, alvos a pardos, os mais externos $2,8-3,9 \times 0,3-0,5 \mathrm{~cm}$, os mais internos $0,8-1,9 \times 0,15-0,20 \mathrm{~cm}$, tricoesclereídes ausentes; carpelos 10-23, completamente adnatos; apêndices estigmatíferos longos, 5,0-10,0 mm compr., lingulados, vináceos com base creme, raios estigmáticos $0,3-0,9 \mathrm{~cm}$ diâm., pardos. Frutos bagas, submersas. Sementes numerosas, 0,4-0,7 $\mathrm{mm}$ compr., arilo aerífero campanulado, translúcido. Material examinado: Aiuaba, 20.III.1991, M.A. Figueiredo 53 (EAC). Beberibe, 11.X.2010, fl., D.J.L. Sousa 137 (EAC). Caridade, 22.IV.2009, fl., A.B.T. Holanda 24 (EAC). Cariré, 10.V.2011, fl., D.J.L. Sousa 121 (EAC). Caucaia, 27.VIII.2008, fl., D.J.L. Sousa 75 (EAC). Fortaleza, 28.VII.1935, fl., F. Drouet 2140 (GH, R). Icapuí, 12.X.2011, f1., D.J.L. Sousa 141 (EAC). Iguatu, 15.V.2010, L.R.O. Normando 197 (EAC). Independência, 12.V.2011, fl., D.J.L. Sousa 127 (EAC). Ipueiras, 11.V.2011, fl., D.J.L. Sousa 125 (EAC). Jijoca de Jericoacoara, 24.VI.2000, fl., L.Q. Matias 305 (EAC). 
Lavras da Mangabeira, 27.VIII.2000, fl., C. Oliveira (EAC-31309). Limoeiro do Norte, 7.III.2011, fl., D.J.L. Sousa 114 (EAC). Morada Nova, 14.X.2011, fl., D.J.L. Sousa 143 (EAC). Russas, 7.III.2011, fl., D.J.L. Sousa 115 (EAC). 29.VI.1982, fl., J.H. Wiersema et al. 2313 (INPA); 30.VI.1982, fl., J.H. Wiersema et al. 2316 (MO, UNA).

Pode ser encontrada na porção leste da América do Sul tropical e subtropical (Wiersema 1987). No Brasil está presente principalmente no domínio da Mata Atlântica com registros para sete estados do nordeste brasileiro (Amaral 2012). Apresenta uma ampla distribuição no estado do Ceará, podendo ser encontrada em corpos d'água temporários na margem de estradas, em depressões nas regiões mais secas no interior do estado e em lagoas costeiras (Fig. 1 - A3, C6, D5, H5, I3, I5, I6). É caracterizada por apresentar uma pseudoviviparidade, onde ramos florais dão origem a novos indivíduos clonais (sensu Sculthorpe 1967). Grob et al. (2006) relata para $N$. prolifera Wiersema algo semelhante, onde formase um pedicelo e uma estrutura floral apresentando peças florais, porém os tecidos meristemáticos que dariam origem ao androceu e gineceu cessam o desenvolvimento e originam folhas e posteriormente novos indivíduos. Sculthorpe (1967) referiu-se a este tipo de estrutura como pseudoestolho. As flores e frutos dessa espécie são raramente observados nas populações presentes no estado, sugerindo que a forma de reprodução predominante na espécie é a vegetativa.

4. Nymphaea lingulata Wiersema. Brittonia 36(3): 215. 1984.

Fig. 3a-d

Rizoma botuliforme a cilíndrico, ca. 2,5 $\mathrm{cm}$ diâm. Folhas ovaladas raro arredondadas; 9,3-24,0 × 9,0-23,0 cm; margem inteira; ápice arredondado, raro mucronado; base cordada a levemente sagitada, lobos com ápice arredondado a mucronado, não imbricados; face adaxial verde, raramente com máculas vináceas, esclereídes 7-15 por $\mathrm{mm}^{2}$, tricoesclereídes ca. 1 por $\mathrm{mm}^{2}$; face abaxial verde a vinácea com máculas enegrecidas; nervação actinódroma não aracnoide, nervuras primárias 17-19; pecíolo 2,0-5,0 mm diâm; glabro; ausência de anel de tricomas na inserção do pecíolo. Flores flutuantes na lâmina d'água, antese noturna, pseudoestolhos ausentes; pedicelo 3,0-6,0 mm diâm., glabro; sépalas 4, ovaladas a amplo elípticas, raro lanceoladas, 4,6-7,8 × 1,7$2,0 \mathrm{~cm}$, verdes, raramente com máculas vináceas, tricoesclereídes presentes; pétalas 8-16, ovaladas a amplo elípticas, 4,5-7,8 × 1,7-2,0 cm, alvas a amareladas, tricoesclereídes presentes, transição de pétalas para estames abrupta; estaminódios petaloides ausentes; estames 50-116, os mais externos pardos, 5,9-4,6 × 0,15-0,20 cm, os mais internos pardos com base vinácea, 1,3-1,8 $\times 0,13$ $0,15 \mathrm{~cm}$, tricoesclereídes ausentes; carpelos 10-14, completamente adnatos; apêndices estigmatíferos longos, 6,0-11,0 mm compr., lingulados, cremes com base vinácea; raios estigmáticos $0,4-1,3$ cm diâm., alaranjados. Frutos bagas, submersas. Sementes numerosas, 0,5-1,0 mm compr., arilo aerífero campanulado, translúcido.

Material examinado: Beberibe, 21.IV.2010, fl., D.J.L. Sousa 106 (EAC). Iguatu, 6.IX.2009, fl., L.Q. Matias 584 (EAC). Ipueiras, 11.V.2011, fl., D.J.L. Sousa 124 (EAC). Irauçuba, 20.IV.2010, fl., D.J.L. Sousa 104 (EAC). Maranguape, 5.VIII.1935, fl., F. Drouet 2174 (GH). Quixeramobim, 13.V.2011, fl., D.J.L. Sousa 132 (EAC). São Benedito, 11.V.2011, fl., D.J.L. Sousa 122 (EAC).

Apresenta uma distribuição restrita ao Nordeste do Brasil, onde é registrada para Caatinga, Cerrado e Mata Atlântica (Wiersema 1987; Amaral 2012). No Ceará, está relacionada a corpos d'água temporários no interior do estado (Fig. 1 - H5). É comumente confundida com Nymphaea lasiophylla, da qual se diferencia por esta apresentar pseudoestolhos submersos, pela ausência de tricoesclereídes no mesofilo foliar e pelas flores com mais de 18 pétalas. Características dos apêndices estigmáticos também facilitam a distinção entre as duas, tendo eles a cor creme com o ápice vináceo em $N$. lasiophylla.

5. Nymphaea pulchella DC. Syst. Nat. 2: 51. 1821 .

Fig. $3 \mathrm{e}-\mathrm{h}$

Rizoma cilíndrico, ca. 3,0 cm diâm. Folhas ovaladas a amplo elípticas; 15,0-44,0 × 14,0-42,0 $\mathrm{cm}$; margem irregular; ápice arredondado, raro levemente retuso; base cordada a levemente sargitada; lobos com ápice agudo a caudado, não imbricados; face adaxial verde a levemente vinácea com máculas vináceas a enegrecidas, esclereídes 7-18 por $\mathrm{mm}^{2}$, tricoesclereídes ausentes; face abaxial vinácea, raro esverdeada, com máculas enegrecidas; nervação actinódroma não aracnóide, nervuras primárias 19-21; pecíolo 2,5-7,0 mm diâm., glabro; ausência de anel de tricomas na inserção do pecíolo. Flores flutuantes 5,0-9,0 cm acima da lâmina d'água, antese diurna, pseudoestolhos ausentes; pedicelo 4,0-7,0 mm diâm., glabro; sépalas 4-5, estreito elípicas a lanceoladas, 3,5-8,0 × 0,8-1,9 cm, verdes a 

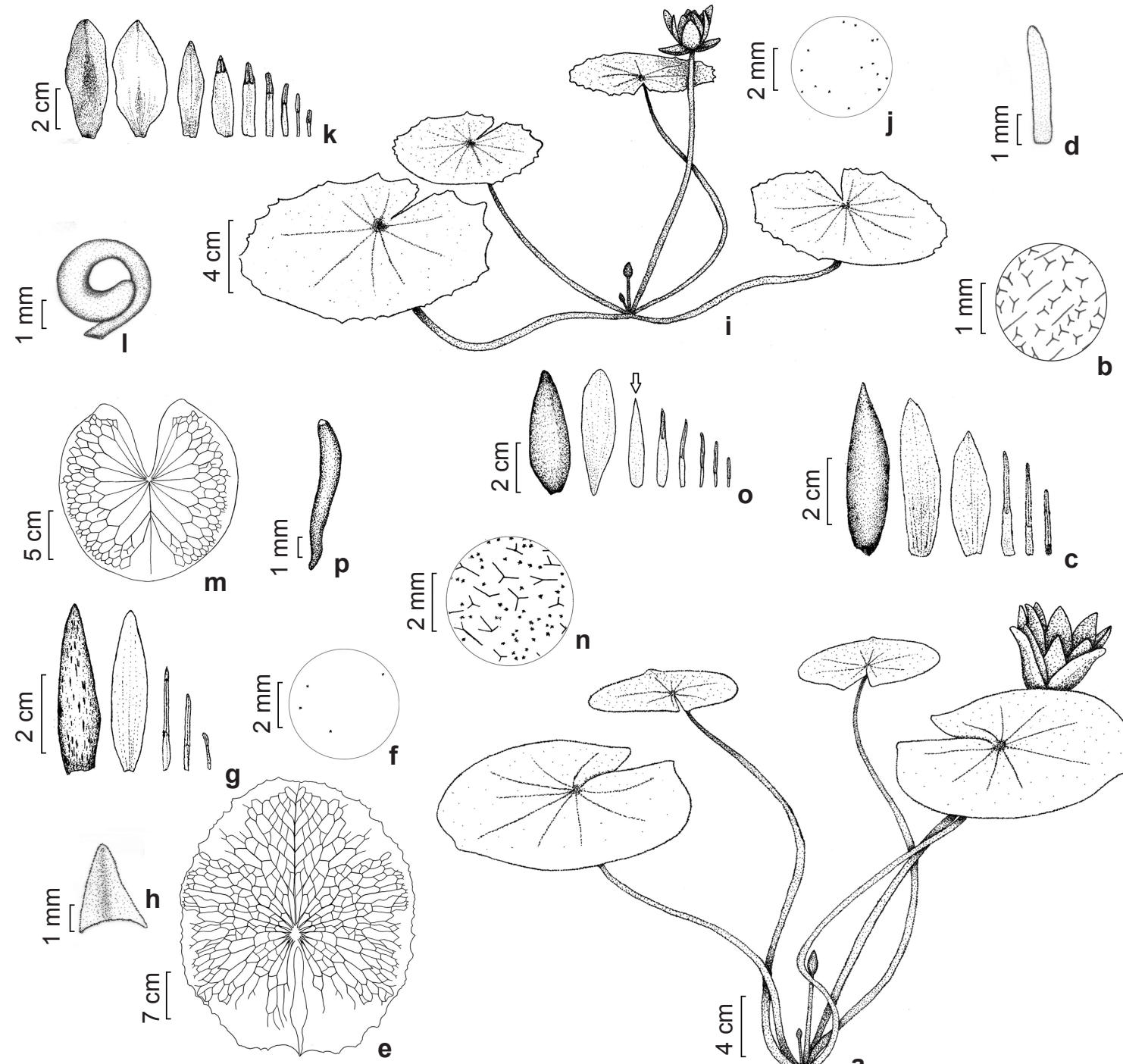

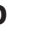

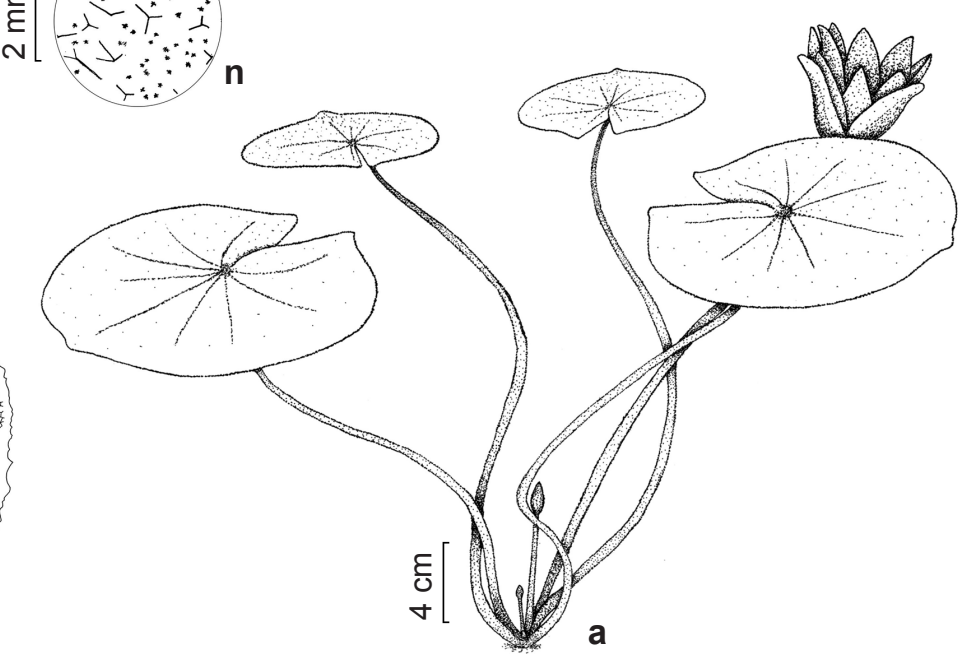

Figura 3 - a-d. Nymphaea lingulata (Normando 19) - a. hábito; b. detalhe da face adaxial do limbo foliar evidenciando a presença de macroesclereídes e de tricoesclereídes; c. peças florais, evidenciando a transição abrupta de pétalas para estames; d. apêndice estigmatífero. e-h. N. pulchella (Sousa 97) - e. face abaxial do limbo foliar evidenciando a nervação; f. detalhe da face adaxial do limbo foliar evidenciando a presença de macroesclereídes escassos e a ausência de tricoesclereídes; g. peças florais evidenciando a transição abrupta de pétalas para estames; h. apêndice estigmatífero. i-1.N. rudgeana (Sousa 76) - i. hábito; j. detalhe da face adaxial do limbo foliar evidenciando a presença de macroesclereídes escassos e a ausência de tricoesclereídes; $\mathrm{k}$. peças florais evidenciando a transição gradual de pétalas para estames; 1. apêndice estigmatífero. m-p. N. tenerinervia (Sousa 116) - m. face abaxial do limbo foliar evidenciando a nervação; $n$. detalhe da face adaxial do limbo foliar evidenciando a presença de macroesclereídes e de tricoesclereídes bifurcados; o. peças florais evidenciando a transição abrupta de pétalas para estames e a presença de estaminódio (seta) entre o verticilo de pétalas e estames; p. apêndice estigmatífero.

Figure 3-a-d. Nymphaea lingulata (Normando 19) -a. habit; b. detail of adaxial side of leaf blade showing the presence of macrosclereids and trichosclereid; c. floral parts, showing the abrupt transition from petals to stamens; d. estigmatiferous appendix. e-h. N. pulchella (Sousa 97) - e. abaxial surface of leaf blade showing the venation; $f$. detail of adaxial side of leaf blade showing the presence of open and sparely macrosclereids and absence of trichosclereid; g. floral parts showing the abrupt transition from petals to stamens; h. estigmatiferous appendix. i-1. N. rudgeana (Sousa 76) - i. habit; j. detail of adaxial side of leaf blade showing the presence of open and sparely macrosclereids and absence of trichosclereid; $\mathrm{k}$. floral parts showing the gradual transition from petals to stamens; 1. estigmatiferous appendix. m-p. N. tenerinervia (Sousa 116) - m. abaxial surface of leaf blade showing the venation; n. detail of adaxial side of leaf blade showing the presence of forked macrosclereids and trichosclereid; 0 . floral parts showing the abrupt transition from petals to stamens and the presence of staminodes (arrow) between whorls of petals and stamens; p. estigmatiferous appendix. 
vináceas com máculas enegrecidas, tricoesclereídes ausentes; pétalas 12-20, elípticas, 3,3-6,0 × 1,3$2,2 \mathrm{~cm}$, brancas, tricoesclereídes ausentes, transição de pétalas para estames abrupta; estaminódios petaloides ausentes; estames 32-66, amarelos, os mais externos $2,3-3,4 \times 0,3-0,4 \mathrm{~cm}$, os mais internos $1,2-1,8 \times 0,2-0,4 \mathrm{~cm}$, tricoesclereídes ausentes; carpelo 14-22, parcialmente conatos na base; apêndices estigmatíferos curtos, 1,5-3,0 $\mathrm{mm}$ compr., triangulares, eretos, amarelos; raios estigmáticos $0,45-1,8 \mathrm{~cm}$ diâm., amarelos. Fruto bagas, submersas. Sementes numerosas, 1,1-1,5 $\mathrm{mm}$ compr., arilo não visto.

Material examinado: Aiuaba, 3.III.2009, E.O. Barros et al. 196 (EAC). Caridade, 5.VIII.2009, fl., D.J.L. Sousa 97 (EAC). Crato, 18.V.2003, L.Q. Matias 477 (EAC). Forquilha, 14.I.1976, fl., A.B. Anderson 226 (INPA). Fortaleza, 5.VIII.1935, fl., F. Drouet 2563 (GH); General Sampaio, 27.V.2007, M.F. Moro et al. 218 (EAC). Independência, 12.V.2011, fl., D.J.L. Sousa 129 (EAC). Iguatu, 13.V.2010, L.R.O. Normando 110 (EAC). Ipueiras, 11.V.2011, fl., D.J.L. Sousa 123 (EAC). Irauçuba, 20.IV.2010, fl., D.J.L. Sousa 106 (EAC). Jati, 4.V.2003, fl., L.Q. Matias 379 (EAC). Monsenhor Tabosa, 12.V.2011, fl., D.J.L. Sousa 126 (EAC).

Registrada para a América do Sul, podendo também ser encontrada no México e algumas ilhas do Caribe (Wiersema et al. 2008). Para o Brasil, Amaral (2012) citou registros da espécie apenas para Ceará e Bahia, porém esta ocorre também em Alagoas, Minas Gerais, Pará, Pernambuco, Rio Grande do Sul, Rio de Janeiro e Sergipe (Benjamin 1959; Wiersema et al. 2008; Bove $\&$ Paz 2009). No interior do Ceará é facilmente encontrada em corpos d'água temporários, nas margens de estradas em pequenas depressões do relevo ou ainda podem formar densas populações nas margens de açudes (Fig. 1 - C4, D5, I3, J5, K6). É o único representante do grupo Apocarpiae para o estado, sendo também a única espécie com antese diurna, facilitando a sua identificação. É comum encontrar material de herbário identificado como Nymphaea ampla (Salisb.) DC., espécie bastante semelhante. Porém Wiersema et al. (2008) descreve para a América do Sul apenas N. pulchella o que, além da distribuição geográfica, apresenta diferença no número de partes florais e em características da borda foliar, ajudando na sua distinção. A espécie é caracterizada por suas folhas amplas e com margens irregulares, vináceas com máculas escuras em ambas as faces e seus apêndices estigmatíferos curtos e triangulares.
6. Nymphaea rudgeana G.Mey. Prim. Fl. Esseq. 198. 1818.

Fig. 3i-1

Rizoma cilíndrico, 2,8-3,9 cm diâm. Folhas oblatas a aredondadas, raramente ovaladas; $8,3-16,9$ $\times$ 9,0-19,0 cm; margem denteada a ondulada; ápice arredondado; base cordada; lobos com ápice denteado, não imbricados; face adaxial vinácea a esverdeada, frequentemente com borda vinácea, esclereídes 1-5 por $\mathrm{mm}^{2}$, tricoesclereídes ausentes; face abaxial vinácea com máculas enegrecidas; nervação actinódroma não aracnóide, nervuras primárias 15-21; pecíolo 3,0-6,0 mm diâm., glabro; ausência de anel de tricomas na inserção do pecíolo. Flores flutuantes 1,0-6,0 cm acima da lâmina d'água, antese noturna, pseudoestolhos ausentes; pedicelo 3,0 6,0 mm diâm., glabro; sépalas 4-5, ovaladas, 3,5-4,7 $\times 0,8-1,9 \mathrm{~cm}$, vináceas a esverdeadas, tricoesclereídes presentes; pétalas 28-32, ovaladas, 3,5-4,3 × 1,3-1,9 $\mathrm{cm}$, alvas, tricoesclereídes presentes, transição de pétalas para estames gradual; estaminódios petaloides ausentes; estames 120-142, alvos a pardos, os mais externos $1,9-2,4 \times 0,5-0,8 \mathrm{~cm}$, os mais internos $0,7-1,0 \times 0,1-0,2 \mathrm{~cm}$, tricoesclereídes ausentes; carpelos 18-22, completamente adnatos; apêndices estigmatíferos longos, 5,0-7,0 mm compr., clavados, curvados, pardos; raios estigmáticos $0,5-0,9 \mathrm{~cm}$ diâm., alaranjados. Frutos bagas, submersas. Sementes numerosas, $0,5-1,2 \mathrm{~mm}$ compr., arilo não visto.

Material examinado: Caucaia, 29.X.2008, D.J.L. Sousa 76 (EAC). Fortaleza, 26.VIII.1935, fl., F. Drouet 2512 (GH). Jijoca de Jericoacoara, 23.VIII.2000, L.Q. Matias 311 (EAC).

É descrita para a Região Norte e Leste da América do Sul e ilhas caribenhas (Wiersema 1987). Apresenta registro em nove estados do Brasil, estando distribuída na Amazônia e Mata Attântica (Amaral 2012). No Ceará, está restrita a lagoas na zona costeira (Fig. 1-A2, C6). Nymphaea rudgeana é caracterizada por suas folhas frequentemente oblatas, porém foram observadas populações com indivíduos com grandes folhas amplamente ovaladas, com bordas irregulares de coloração vinácea. A espécie destaca-se, além de sua ocorrência restrita ao litoral do estado, por apresentar apêndices estigmatíferos bastante desenvolvidos, curvados e totalmente pardos diferindo dos apêndices de $N$. amazonum que possuem ápices rosáceos.

7. Nymphaea tenerinervia Casp. Fl. bras. 4(2): 178-179, t. 36. 1878.

Fig. $3 m-p$

Rizoma botuliforme a cilíndrico, $1,5-2,0 \mathrm{~cm}$ diâm. Folhas arredondadas, 7,3-16,8 ×6,8-15,7 cm; margem inteira; ápice arredondado; base arredondada a levemente cordada; lobos com ápice arredondado, 
raramente imbricados; face adaxial verde raramente com máculas vináceas, esclereídes 10-14 por $\mathrm{mm}^{2}$, tricoesclereídes ca. 1 por $\mathrm{mm}^{2}$, bifurcados; face abaxial vinácea raramente com borda esverdeada, frequentemente com máculas enegrecidas; nervação actinódroma não aracnóide, nervuras primárias 15-17; pecíolo 2,0-4,0 mm diâm., glabro; ausência de anel de tricomas na inserção do pecíolo. Flores flutuantes na lâmina d'água, antese noturna, pseudoestolhos ausentes; pedicelo 3,0-5,0 mm diâm., glabro; sépalas 4, ovaladas a lanceoladas, 3,6-5,5 × 0,9-1,5 cm, esverdeadas raramente com máculas vináceas, tricoesclereídes presentes; pétalas 12-20, ovaladas, 4,4-4,6 × 1,5-1,8 cm, alvas, tricoesclereídes presentes, transição de pétalas para estames gradual; estaminódios petaloides 3-5 entre as pétalas e os estames; estames 58-84, os mais externos pardos $3,0-3,5 \times 0,3-0,5 \mathrm{~cm}$, os mais internos pardos com base vinácea, 1,6-1,8 $\times 0,5-0,1 \mathrm{~cm}$, tricoesclereídes ausentes; carpelos 12-20, completamente adnatos; apêndices estigmatíferos longos, 5,0-6,0 mm compr., clavados, eretos, vináceos com ápice e base creme; raios estigmáticos $0,4-0,6 \mathrm{~cm}$ diâm., pardos a alaranjados. Frutos não vistos. Sementes não vistas. Material examinado: Beberibe, 11.X.2011, fl., D.J.L. Sousa 138 (EAC). Caucaia, 29.III.2011, D.J.L. Sousa 116 (EAC). 1859, fl., Fr. Allemão et al. 34 (R). 29.VI.1982, fl., J.H. Wiersema et al. 2314 (MO, UNA).

Inicialmente descrita apenas para as Regiões Norte e Nordeste do Brasil, atualmente a espécie apresenta registros, apesar de não confirmados, também para a Guiana (Wiersema 1987). Apresenta registro em sete estados do Brasil estando distribuídos na Amazônia e Mata Atlântica brasileira (Amaral 2012). No Ceará a espécie está restrita a áreas alagadas na zona costeira (Fig. 1-C6, D7). Nymphaea tenerinervia é caracterizada por suas pequenas flores com apêndices clavados, eretos e vináceos com ápice e base creme. Apresenta um verticilo de estruturas laminares com ápice agudo entre as pétalas e os estames. Estes são morfologicamente mais próximos de estames, porém com ausência de tecas, sendo considerados estaminódios.

\section{Agradecimentos}

Ao Victor Gonçalves Távora pelas ilustrações das peças florais. Ao biólogo Marcelo Telles (PPGERN/UFC) pela preparação do modelo de mapa.

\section{Referências}

Amaral, M.C.E. 2006. Nymphaeaceae In: Barbosa, M.R.V.; Sothers, C.; Mayo, S.J.; Gamarra-Rojas, C.F.L. \& Mesquita, A.C. (eds.). Checklist das plantas do nordeste brasileiro: angiospermas e gimnospermas. Ministério da Ciência e Tecnologia, Brasília. 49p.

Amaral, M.C.E. 2012. Nymphaeaceae In: Forzza, R.C. et al. (eds.). Lista de espécies da flora do Brasil. Jardim Botânico do Rio de Janeiro. Disponível em $<$ http://floradobrasil.jbrj.gov.br/2010/FB000173> Acesso 15 Jun 2012.

Angiosperm Phylogenetic Group. 2009. An update of the Angiosperm Phylogenetic Group classification for the orders and families of flowering plants: APG III. Botanical Journal of the Linnean Society 161: $105-121$.

Benjamin, D.S. 1959. Nymphaeaceae da cidade do Rio de Janeiro. Rodriguésia 21-22: 285-287.

Bertol, E.; Fineschi, V.; Karch, S.B.; Mari, F. \& Riezzo, I. 2004. Nymphaea cults in ancient Egypt and the New World: a lesson in empirical pharmacology. Royal Society of Medicine Press 97: 84-85.

Borsch T.; Hilu, K.W.; Quandt, D.; Wilde,V.; Neinhuis, C. \& Barthlott W. 2003 Non-coding plastid trnTtrnF sequences reveal a well resolved phylogeny of basal angiosperms. Journal of Evolutionary Biology 16: 558-576.

Borsch T.; Löhne, C. \& Wiersema, J.H. 2008. Phylogeny and evolutionary patterns in Nymphaeales: integrating genes, genomes and morphology. Taxon. 57: 1052-1081.

Bove, C.P. \& Paz, J. 2009. Guia de campo das plantas aquáticas do Parque Nacional da Restinga de Jurubatiba, Rio de Janeiro, Brasil. Museu Nacional, Rio de Janeiro. 176p.

Caspary, R. 1878. Nymphaeaceae. In: Flora brasiliensis. Leipzig, Monachi. Pp. 129-184.

Ceska, A. 1986. More on techniques for collecting aquatic and marsh plants. Annals of the Missouri Botanical Garden 73: 825-827.

Conard, H.S. 1905. The waterlilies. A monograph of the genus Nymphaea. Lord Baltimore Press, Baltimore. 279 p.

Dezhi, F.; Wiersema, J.H. \& Padegett, D. 2011. Nymphaeaceae. In: Flora of China. Science Press \& Missouri Botanical Garden Press. Disponível em $<$ http://www.efloras.org/florataxon.aspx $>$. Acesso 15 Jun 2012.

Duke, J.A. 1963. Nymphaeaceae. In: Flora of Panama. Annals of the Missouri Botanical Garden 49: 456.

Endress, P.K. 2010. The evolution of floral biology in basal angiosperms. Philosophical Transactions of the Royal Society B 365: 411-421.

Grob, V.; Moline, P.; Pfeifer, E.; Novelo, A. R. \& Rutishauser, R. 2006. Developmental morphology of branching flowers in Nymphaea prolifera. Journal of Plant Research 119: 561-570.

Harris, J.G \& Harris, M.W. 1994. Plant identification terminology: an illustrated glossary. Spring Lake Publishing, Utah. 216p. 
Haynes, R.R. 1984. Techniques for collecting aquatic and marsh plants. Annals of the Missouri Botanical Garden 71: 229-231.

Hyde, M.A.; Wursten, B.T.; Ballings, P. \& Dondeyne, S. 2012. Nymphaeaceae. In: Flora of Mozambique. Disponível em $<$ http://www.mozambiqueflora.com/ speciesdata/family.php?family_id=152>. Acesso 15 Jun 2012.

IPNI. [continuously updated]. The International Plant Names Index. Disponível em <http://www.ipni. org $>$. Acesso 7 Set 2010.

Ito, M. 1987. Phylogenetic systematics of Nymphaeales. The Botanical Magazin. 100: 17-35.

Jacobs, S.W.L. \& Porter, C.L. 2007. Nymphaeaceae. In: Wilson, A.J.G. (ed.). Flora of Australia. Australian Government Publishing Service, Canberra. Pp. 233-243.

Krell, F.T.; Hirthe, G.; Seine, R. \& Porembski, S. 2003. Rhinoceros beetles pollinate water lilies in Africa (Coleoptera: Scarabaeidae: Dynastinae; Magnoliidae: Nymphaeaceae). Ecotropica, 9: 103-106.

Les, D.H.; Garvin, D.K. \& Wimpee, C.F. 1991. Molecular evolutionary history of ancient aquatic angiosperms. Proceedings of the National Academy of Sciences of the United States of America 88: 10119-10123.

Les, D.H.; Schneider, D.J.; Padgett, P.S.; Soltis, D.E. \& Zanis, M. 1999. Phylogeny, classification and floral evolution of water lilies (Nymphaeaceae; Nymphaeales): a synthesis of non-molecular, rbc1, matK, and $18 \mathrm{~S}$ rDNA data. Systematic Botany 24: 28-46.

Löhne, C.; Borsch, T. \& Wiersema, J.H. 2007. Phylogenetic analysis of Nymphaeales using fast-evolving and non-coding chloroplast markers. Botanical Journal of the Linnean Society 154: 141-163.

Matias, L.Q. 2007. O gênero Echinodorus (Alismataceae) no domínio da caatinga brasileira. Rodriguésia 58: 743-774.

Matias, L.Q. 2010. A synopsis of Alismataceae from the Semi-Arid region of Northeastern. Brazil. Revista Caatinga 23: 46-53.
Matias, L.Q.; Amado, E.R \& Nunes, E.P. 2003. Macrófitas aquáticas da lagoa de Jijoca de Jericoacoara, Ceará. Acta Botanica Brasilica 17: 623-631.

Matias, L.Q. \& Irgang, B.E. 2006. Taxonomy and distribution of Sagittaria (Alismataceae) in northeastern Brazil. Aquatic Botany 84: 183-190.

Matias, L.Q. \& Sousa, D.J.L. 2011. Alismataceae no estado do Ceará, Brasil. Rodriguésia 62: 887-900.

Pott, V.J. 1998. A família Nymphaeaceae no Pantanal, Mato Grosso e Mato Grosso do Sul, Brasil. Acta Botanica Brasilica 12: 183-194.

Pott, V.J. \& Pott, A. 2000. Plantas aquáticas do Pantanal. Embrapa, Brasília. 401p.

Radford, A.E.; Dickison, W.C.; Massey, J.R. \& Bell, C.R. 1974. Vascular plant systematics. Harper \& Row, New York. 891p.

Reveal, J.L. \& Chase M.W. 2011.APG III: bibliographical information and synonymy of Magnoliidae. Phytotaxa 19: 71-134.

Sculthorpe, C.D. 1967. The biology of aquatic vascular plants. Edward Arnold, London.

Souza, V.C. \& Lorenzi, H. 2008. Botânica sistemática: guia ilustrado para identificação das famílias de fanerógamas nativas e exóticas no Brasil, baseado em APG II. $2^{\text {a }}$ ed. Instituto Plantarum, São Paulo. $704 \mathrm{p}$.

Thiers, B. [continuously updated]. Index Herbariorum: a global directory of public herbaria and associated staff. New York Botanical Garden's Virtual Herbarium. Disponível em $<$ http://sweetgum.nybg. org/ih/>. Acesso 10 Nov 2010.

Wiersema, J.H. 1987. A monograph of Nymphaea subgenus Hydrocallis (Nymphaeaceae). Systematic Botany Monographs 16: 1-112.

Wiersema, J.H.; Novelo, A.R. \& Bonilla-Barbosa, J.R. 2008. Taxonomy and typification of Nymphaea ampla (Salisb.) DC. sensu lato (Nymphaeaceae). Taxon 57: 967-974.

Yoo, M.J.; Bell, C.D.; Soltis, P.S. \& Soltis, D.E. 2005. Divergence times and historical biogeography of Nymphaeales. Systematic Botany 30: 693-704.

\section{Lista de exsicatas}

Allemão, Fr. et al. 34(7). Anderson, A.B. 226(5). Barros, E.O. et al. 196(5). Bove, C.P. et al. 1930(3). Castro, A.S.F. 2352(1). Drouet, F. 2140(3), 2174(4), 2292(3), 2486(3), 2511(1), 2512(6), 2563(5). Figueiredo, M.A. 53(3). Holanda, A.B.T. 24(3). Matias, L.Q. 199(3), 305(3), 311(6), 312(1), 379(5), 477(5), 570(1), 578(1), 584(4). Moro, M.F. et al. 218(5). Normando, L.R.O. 110(5), 111a(4), 127(3), 129(4), 130(5), 144(4), 170(4), 171(5), 19(4), 197(3), 217(3), 222(5), 223(4), 231(5), 247(4), 263(3), 306(5), 311(4), 348(5), 37(4), 381(4), 392(4), 444(4), 455(4), 478(4), 518(4), 519(4), 520(2), 53(5), 54(4). Oliveira, C. s.n. EAC-31309(3). Sousa, D.J.L. 132(4), 132(1), 104(4), 105(5), 106(5), 114(3), 115(3), 116(7), 117(7), 118(7), 119(7), 120(1), 121(3), 122(4), 123(5), 124(4), 125(3), 126(5), 127(3), 128(3), 129(5), 130(3), 131(1), 133(2), 134(4), 135(2), 137(3), 138(7), 139(3), 141(3), 142(1), 143(3), 52(3), 64(1), 75(3), 76(6), 97(5). Wiersema, J.H. etal. 2312(1), 2313(3), 2314(7), 2315(2), 2316(3). 